\title{
Is it safe to initiate the minimally invasive aortic valve replacement technique in an institution with experience in cardiovascular surgery?
}

\author{
Rafael Meza*, Alejandro Escobar, Gloria Franco, Alejandra Echeverri, Jose David Serna \\ From World Society of Cardiothoracic Surgeons 25th Anniversary Congress, Edinburgh \\ Edinburgh, UK. 19-22 September 2015
}

\section{Background/Introduction}

The implementation of new surgical techniques in an institution requires the suitable training of an interdisciplinary group (surgeons, anesthesiologists, nurses, doctors, ICU); the initial results, known as learning curve, are those that define the successful continuity of said techniques in the institutions, therefore they are of utmost importance.

\section{Aims/Objectives}

Compare the pertaining patients to the learning curve group with the rest, both subjected to aortic valve replacement by the minimally invasive technique (MICS) conducted by the same group of cardiovascular surgeons, evaluating surgery time, postoperative complications, hospital stay and mortality.

\section{Method}

83 consecutive cases were studied, with an age of $62.54 \pm$ 12.60 years between 30 and 84 years, of them 70 (84.30\%) were given an implanted Biological prosthesis and 13 $(15.70 \%)$ a mechanical prosthesis, defined the learning curve as the first 25 procedures (Learning Curve) and compared with the 58 remaining procedures (The Rest).

\section{Results}

The cross clamp time was $71.84 \pm 10.85 \mathrm{~min}$ in the learning curve and $79.86 \pm 21.079$ in the Rest $\mathrm{p}=0.076$ and the perfusion time $83.32 \pm 12.95 \mathrm{~min}$ in the learning curve and $95.02 \pm 26.21 \mathrm{~min}$ in the rest $\mathrm{p}=0.057$ without significant differences. The main complications are shown in table 1 without significant differences.
Table 1

\begin{tabular}{|c|c|c|c|c|c|}
\hline & \multicolumn{5}{|c|}{$\begin{array}{c}\text { Complication Learning Curve } \\
\text { Rest } \\
\end{array}$} \\
\hline & & $\mathrm{n} \%$ & & $\mathrm{n} \%$ & $\mathbf{p}$ \\
\hline Arrhythmias & 2 & $8.00 \%$ & 9 & $15.50 \%$ & 0.354 \\
\hline Mediastinitis & 0 & $0.00 \%$ & 2 & $3.40 \%$ & 0.347 \\
\hline SSI & 1 & $4.00 \%$ & 1 & $1.70 \%$ & 0.535 \\
\hline Reintervention due to bleeding & 1 & $4.00 \%$ & 3 & $5.20 \%$ & 0.819 \\
\hline Death $<30$ days & 0 & $0.00 \%$ & 2 & $3.40 \%$ & 0.347 \\
\hline
\end{tabular}

Hospital stay $6.72 \pm 4.04$ days Vs $7.16 \pm 5.071$ days $\mathrm{p}=0.705 \mathrm{did}$ not present statistically significant differences.

\section{Discussion/Conclusion}

The learning curve in aortic valve replacement conducted by MICS can be initiated safely with a low morbimortality.

Published: 16 December 2015

doi:10.1186/1749-8090-10-S1-A172

Cite this article as: Meza et al:: Is it safe to initiate the minimally invasive aortic valve replacement technique in an institution with experience in cardiovascular surgery? Journal of Cardiothoracic Surgery 2015 10(Suppl 1):A172. 